INTERNATIONAL DESIGN CONFERENCE - DESIGN 2018

https://doi.org/10.21278/idc.2018.0221

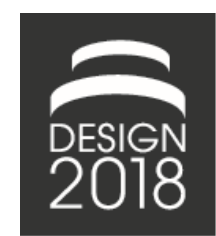

\title{
SPECIFICATION TECHNIQUE FOR AUGMENTED REALITY BASED PRODUCT SERVICE SYSTEMS
}

\author{
D. Röltgen, F. Wortmann, H. Anacker and R. Dumitrescu
}

\begin{abstract}
As one of the key technologies of digitalization, Augmented Reality (AR) provides significant innovation potentials for the product service business. However, the design of AR-based product service systems proves to be challenging due to interdependencies of product, service and AR functionalities. In this paper, a semi-formal, domain-spanning specification technique is presented. It helps companies to systematically create concepts for product service systems, taking into account the technologyspecific requirements of $\mathrm{AR}$, and enables a transparent communication between the domains involved.
\end{abstract}

Keywords: augmented reality (AR), product-service systems (PSS), systems engineering (SE), design methods

\section{Introduction}

In recent years, there has been a significant change in the traditional product portfolio of manufacturing companies in industrial goods markets. Due to the increasing uniformity of physical products in terms of quality and price, it is becoming very rare for competitive advantages to be solely based on the traditional product business ( $\mathrm{Li}$ et al., 2016). In order to differentiate themselves from competition and solve customer problems as comprehensively as possible, companies are enhancing their physical products with additional, increasingly digital services ( $\mathrm{Li}$ et al., 2016). This paradigm shift is also referred to as Servitization in Manufacturing (Herterich et al., 2015) and reflects the economic transformation to a service society at the corporate level ("tertiarization of industry"). The combination of tangible products and intangible services leads to highly integrated, hybrid solutions, so-called product service systems (PSS) (Tukker and Tischner, 2006; Aurich et al., 2007).

The shift towards product service systems is accelerated by innovation potentials that arise from the ongoing digitalization. Rapid advances in information and communication technology (ICT) transform both products as well as services. By integrating sensors, actuators and advanced information processing technology, products move from mechatronic systems towards cyber-physical systems (CPS), which interact with both the physical and digital world (Broy, 2010; Porter and Heppelman, 2017). The data collected, processed and exchanged by these systems allows for new service offerings, so-called smart services, which are tailored to satisfy individual customer needs according to a specific situation or context (acatech, 2015).

\subsection{AR-based product service systems}

The main driver for the digital transformation of product service systems is the rise and progress of digitally enabled technologies. One of the key technologies that is considered to have a significant impact on the industrial value creation is Augmented Reality (Rüßmann et al., 2015; Porter and Heppelmann, 2017). It enables real environments to be enriched with additional virtual content (Milgram et al., 1994; Azuma, 1997). For example, operating or repair instructions can be visualized as a 3D animation superimposed on 
a physical machine (see Figure 1), or experts can be made available globally via remote support. By delivering relevant information directly into the context in which it is required, AR builds a bridge between the physical and the digital worlds. It therefore allows to fully exploit the economic potential hidden in the wealth of digital data that is now available (Porter and Heppelman, 2017). Although its origins date back to the 1960s, AR was in its fledgling stages for a long a time due to technical limitations. However, with the increasing performance and miniaturization of key enabling technologies, such as microchips, and simultaneously decreasing costs, sufficiently powerful and affordable hard- and software systems are now available which enable an efficient use of AR in industrial applications (Blau et al., 2017).

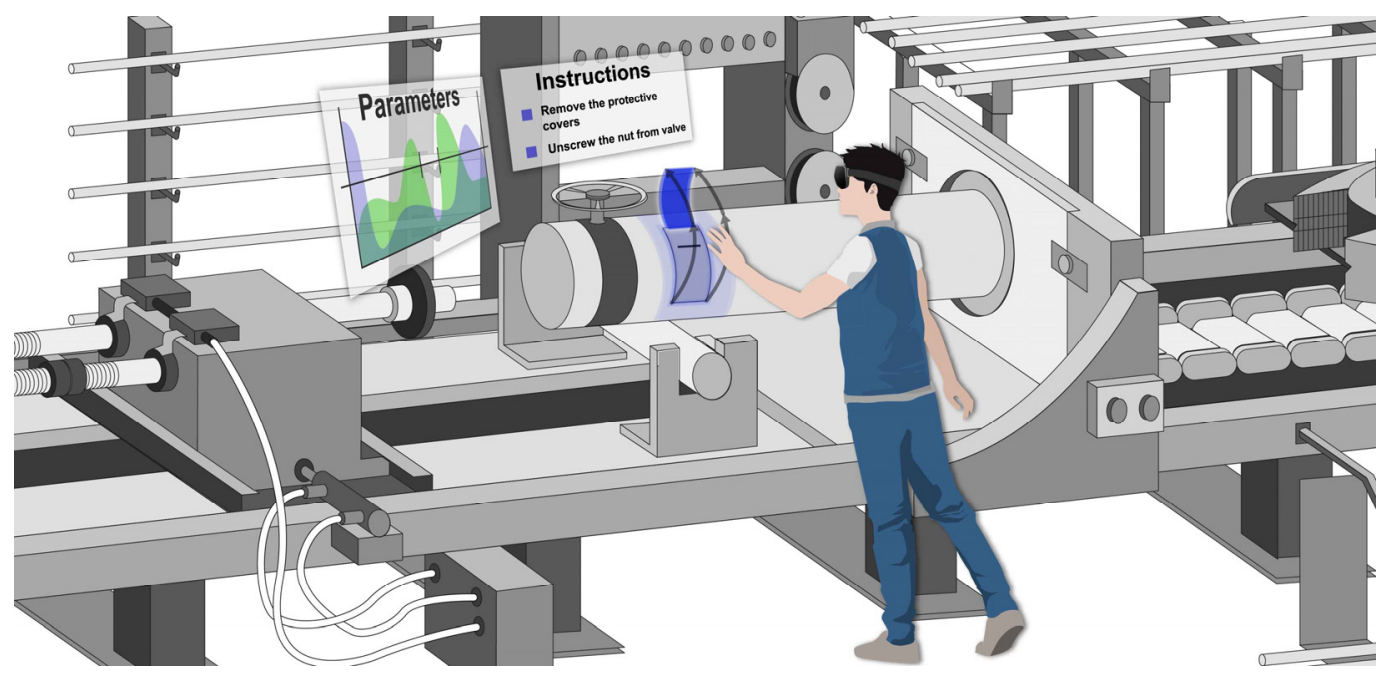

Figure 1. A machine operator is visually guided to repair a plant with the help of $A R$

Besides improving performance across the internal value chain, the capabilities of AR can significantly stimulate innovation for the product service business (Porcelli et al., 2013; Porter and Heppelmann, 2017). The integration of AR functionalities in product service systems leads to so-called AR-based product service systems which are the subject of this paper and which we define as follows:

An AR-based product service system is a customer-oriented combination of products and services in which AR forms the technical basis for additional product functions and/or the provision of services.

The spectrum of potential AR applications covers the entire lifecycle of a product service system and ranges from the evaluation of product concepts in early development stages (e.g. AR-based conjoint analysis) to supporting the customer in using the product (e.g. AR-based operating instructions) or assisting its disposal at the end of the lifecycle (e.g. AR-based disassembly support). The enormous economic potential of AR is also reflected in the figures of current market forecasts for AR: according to DigiCapital, a market volume of US\$ 58 billion is expected for 2020, which corresponds to an increase by a factor of more than 300 compared to US\$ 181 million in 2011 (Glockner et al., 2014; DigiCapital, 2017). A recent study conducted by PTC implies that a large proportion of this forecast will result from the use of AR in the product service business, as greater sales revenues, an enhanced enduser experience, product differentiation and better servicing are among the most frequently mentioned strategic goals of AR use (Porter and Heppelmann, 2017).

\subsection{Challenges in the design process of AR-based product service systems}

However, when trying to utilize AR for their product service business, companies are faced with several challenges. Due to the increasing spread of information and communication technology, the planning and specification of AR-based product service systems is a highly interdisciplinary task: mechanical, electrical, control and software engineers are required as well as staff from service and management departments. The variety and diversity of the domains involved result in an increased complexity of the design process, which in turn requires an efficient communication across the different domains, starting 
at an early stage. Since product and service are often closely interlinked, transparency regarding interdependencies is crucial, especially when implementing changes at an advanced stage which often have an effect on several domains (Klinger and Becker, 2012). For example, adding AR functionalities to existing product service systems might require to add new components to the product (e.g. communication module), they might also have an effect on service processes (e.g. customers doing self-service) or might demand new resources (e.g. know-how, technical infrastructure). In order to cope with complexity and ensure a common understanding of the task at hand, (model-based) systems engineering approaches are used. However, the majority of these approaches are solely focussed on either physical products (Gausemeier et al., 2014) or services (Tsai, 2005), while design methodologies with an integrated view on product service systems are often too generic or too resource-intensive to use (Gräßle et al., 2010).

Furthermore, none of the available approaches considers the specific technology-related requirements that come up with AR. According to Craig (2013), the primary constraints of AR that have to be taken into account in the development process can be divided into two categories: technological and environmental. Concerning technological constraints, requirements based on the limited capabilities of mobile AR devices have to be considered (e.g. computing performance, display capability). Furthermore, environmental influences have a significant effect on the proper functioning of an AR application. For example, since most AR devices use computer vision for tracking, it is essential to ensure that there is enough ambient light of the appropriate wavelength in the environment to allow the device to calculate its position and orientation. Other environmental constraints, for instance, result from a strong dependence on a reliable network connection (e.g. data transfer via WiFi), ambient sounds (e.g. when using voice control), magnetic fields (e.g. electromagnetic interference) or temperatures (e.g. hot areas). In order to avoid costly iterations, it is necessary to consider these constraints at an early stage.

To overcome the challenges mentioned above, we present a semi-formal, domain-spanning specification technique that (1) helps companies to systematically create concepts for product service systems, taking into account the technology-specific requirements of AR, and (2) enables a transparent communication between the various stakeholders of the different domains involved.

\section{Specification technique}

The specification technique consists of two main components: a modeling concept containing a set of partial models to describe the most important aspects of the product service system, as well as a procedure model that gives step-by-step instructions on how to specify the principle solution of an ARbased product service system using the partial models of the modeling concept. In the following sections, the modeling concept and the procedure model are discussed in detail.

\subsection{Modeling concept}

In order to specify AR-based product service systems in a holistic, domain-spanning way, the modeling concept contains a set of partial models with each partial model reflecting a certain aspect of the product service system (e.g. functions, requirements). The partial models are closely interconnect, with relations represented between the constructs of the partial models, allowing transparency with respect to interdependencies. Thus, the modeling concept provides a platform for the coordination of changes across the domains as well as the traceability of requirements along the product service system lifecycle. Based on CONSENS (CONceptual design Specification technique for Engineering of complex Systems), the modeling concept contains partial models covering the aspects requirements, environment, functions, active structure and behaviour (Gausemeier et al., 2014). In order to be able to also describe service-related aspects, additional partial models are added to the modeling concept. As generally recognised in scientific literature, there are three structural dimensions that constitute services: while the potential dimension is focussed on the ability of the service provider to perform the service according to the needs and requirements of the customer, the process dimension considers services as a sequence of activities, whereas the result dimension focusses on the results of the process, since they represent the actual benefit of the service (Bruhn and Stauss, 2009; Leimeister, 2012). In the modeling concept each service dimension is represented by a dedicated partial model, namely resources (potential dimension), process (process dimension) and result (result dimension). Figure 2 shows the modeling concept with the partial models as well as their logical relations. 


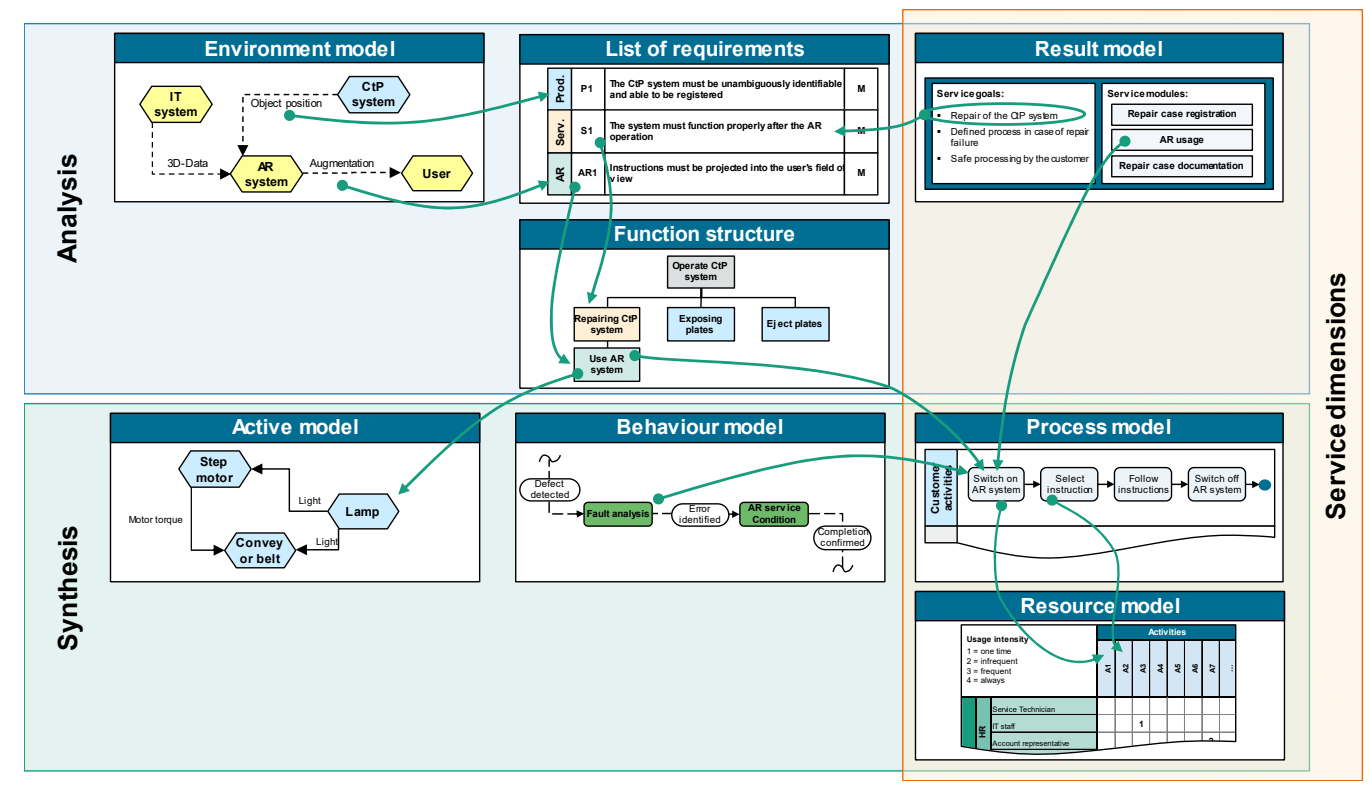

Figure 2. Modeling concept for specifying AR-based product service systems

The modeling concept shown in Figure 2 is generally applicable to describe product service systems. It can be used to create new product service concepts from scratch, to integrate AR-based services into existing products (e.g. adding an AR-based repair service to a specific machine that had no service before), as well as to add AR functionalities to existing product service combinations (e.g. enhancing an existing repair service with AR). Furthermore, additional tools and checklists are attached to selected partial models to help consider the technology-specific requirements of AR at an early stage (e.g. guiding questions supporting the definition of requirements). In the following, the procedure model is described. In this context, the partial models as well as the tools and checklists are also discussed in more detail.

\subsection{Procedure model}

While the modeling concept allows to describe the most important aspects of a product service system, it does not provide instructions on how to use the partial models. That is why a procedure model has been developed. It provides information on a reasonable sequence according to which the partial models of the modeling concept should be implemented. It should be noted, however, that depending on the specific situation and purposes of the specification other processing sequences might be suitable. Since the specification process is highly iterative, it might be necessary to repeat some steps of the procedure model several times to achieve the desired results and ensure consistency among the partial models.

As described in Section 2.1., the initial situation when using the specification technique can vary in terms of which components of the product service system already exist (e.g. machine with service, machine without service or neither a machine nor a service). Since in most cases AR functionalities will be added to either an existing product (e.g. machine) or a product service system (e.g. machine with conventional repair service), the procedure model which is described in the following is based on the assumption that at least a system model of the existing product is available. In this context, the term system model refers to having an environment model, a list of requirements, a function structure, an active structure as well as a behaviour model for the physical product, according to the notation of CONSENS. This means that the specification technique is primarily focused on analysing adaptation needs that result from integrating AR service components. Besides the system model, it is required to have a precise idea of which AR application should be implemented when starting with the specification technique. Methodological support for identifying the potentials of AR for the product service business has been recently presented by the authors (Röltgen et al., 2017).

Basically, the procedure is divided into four phases. The first phase focusses on a requirements analysis. Based on the specific AR application that is to be implemented, requirements are derived using the environment model and result model and are collected in a list of requirements. In the second phase, 
a function analysis is conducted. Based on the requirements, functions of the product service system are determined and hierarchically structured. Within the synthesis, as the third phase, the physical product is defined in terms of the system architecture (active structure) and behaviour (behaviour model), while the service is detailed in terms of its processes (process model). The focus in this phase will often be on the identification of specific adaptation requirements for the product and the service due to the integration of AR. The last phase is devoted to deriving a plan of action, containing measures for the further implementation based on the previously collected information. Besides the partial models that are used in the procedure model, the communication between the various stakeholders is supported by a so-called AR Configuration Canvas which structures the most important aspects into several layers. Figure 3 shows the procedure model in the form of a phase/milestone diagram.

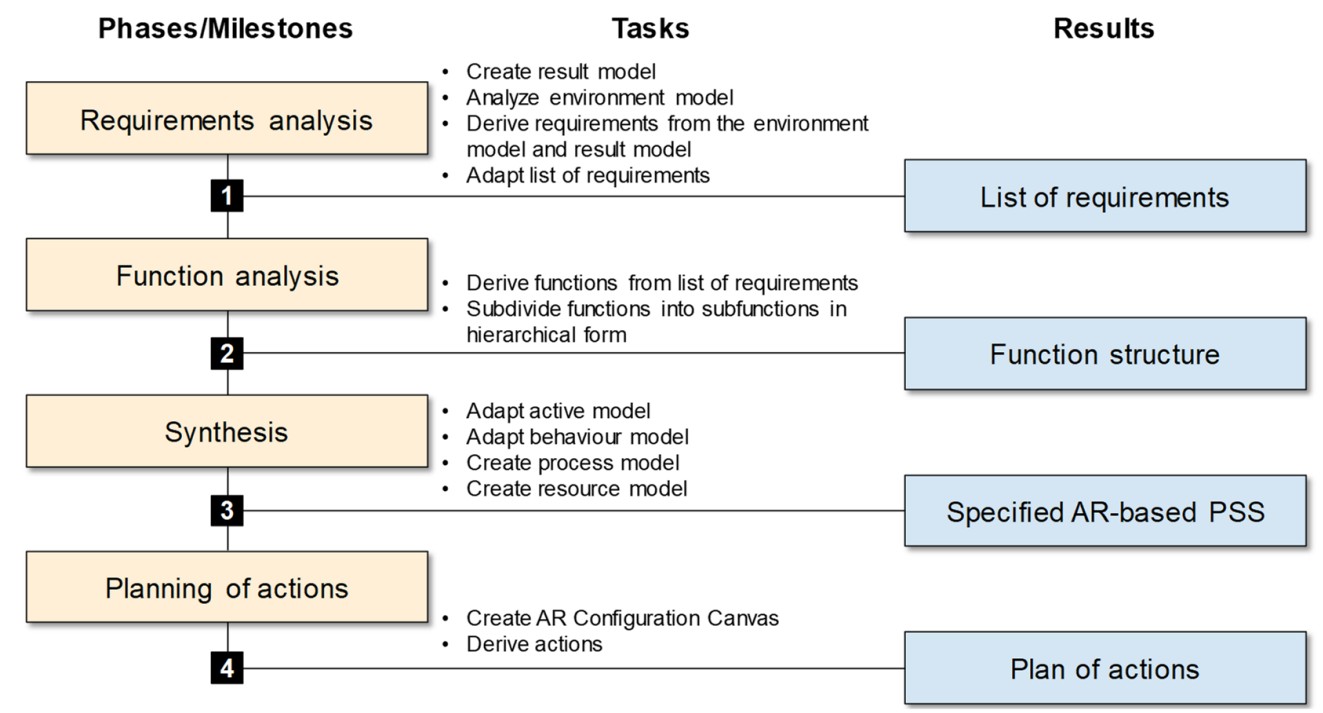

Figure 3. Procedure model for specifying AR-based product service systems

In the following sections, the specification technique is illustrated by an industrial use case from the current joint research project "AcRoSS - Instruments for the Implementation of AR-based Product Service Systems" which is funded by the German Federal Ministry for Economic Affairs and Energy (BMWi). As part of the project, the use of AR is analysed for supporting repair processes of Computerto-Plate (CtP) systems which are used in the printing process of newspapers and magazines. Especially for daily newspapers, it is essential to integrate as much information as possible into each issue, which means that the actual printing process takes place in a very short time frame and is therefore extremely time-critical. By offering AR-enhanced repair services, a provider of CtP systems could enable customers to carry out repair procedures by themselves, resulting in advantages for both sides. In case of failures, the customer can quickly repair the machine and therefore increase the machine availability. In addition, the customer's plant technicians become more knowledgeable and can maintain the machine more independently than before. From the point of view of the CtP provider, the AR service can result in cost savings since the availability of the in-house service technicians is increased, as they only have to move out for more complex repair processes. In the project, the specification technique has been successfully validated and used to implement the AR-enhanced repair service at an advanced pilot stage.

\subsection{Requirements analysis}

As explained in Section 2.2. and depicted in Figure 4, initial input for the specification technique is a system model of the product as well as a description of the AR application that should be implemented. Concerning the latter, a profile of an AR application scenario is used, as proposed by Röltgen et al. (2017). The profile is divided into different sections. A short description provides a brief overview of the application. In addition, the service is also assigned to the product service system lifecycle from the customer's point of view. Furthermore, the profile contains, among others, a description of the benefits from the point of view of the customer and the provider as well as information on the technical complexity and 
whether the customer or provider will be using the AR device. Besides the AR application profile, another input is a system model for the existing product which will be analysed in terms of adaptation needs.

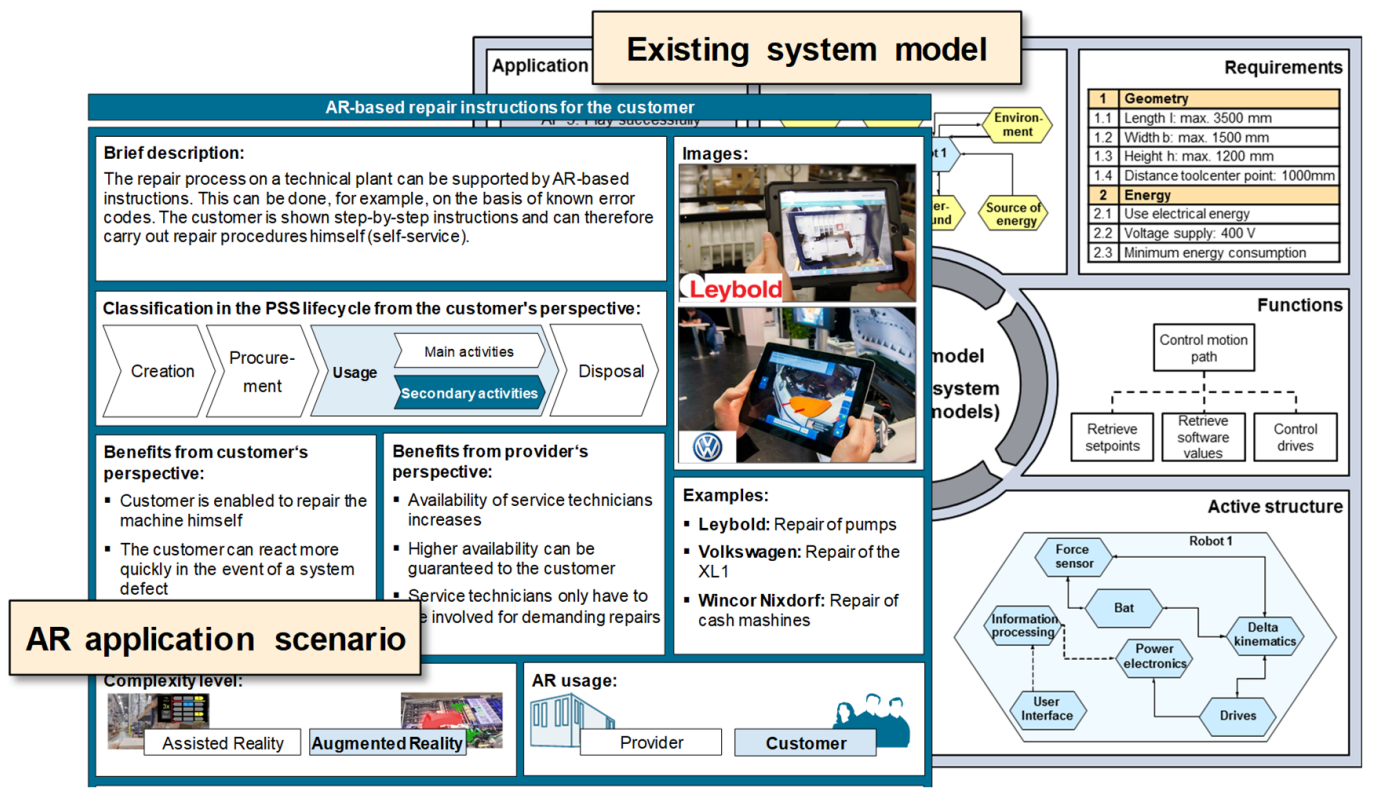

Figure 4. Initial input for using the specification technique

Based on the AR application scenario profile, the result model is defined. It is used to characterize the desired goal of the service in more detail and represents the so-called result dimension of a service. As shown in Figure 5, the result model includes a brief description of the service and the key objectives, a list of the service attributes according to the Kano model (Kano et al., 1984) as well as an overview of the required service modules which aggregate the most important process sequences (e.g. training the customer in using the AR system, documenting the repair process etc.). Based on the information of the result model, requirements from a service perspective can be derived and added to the list of requirements.

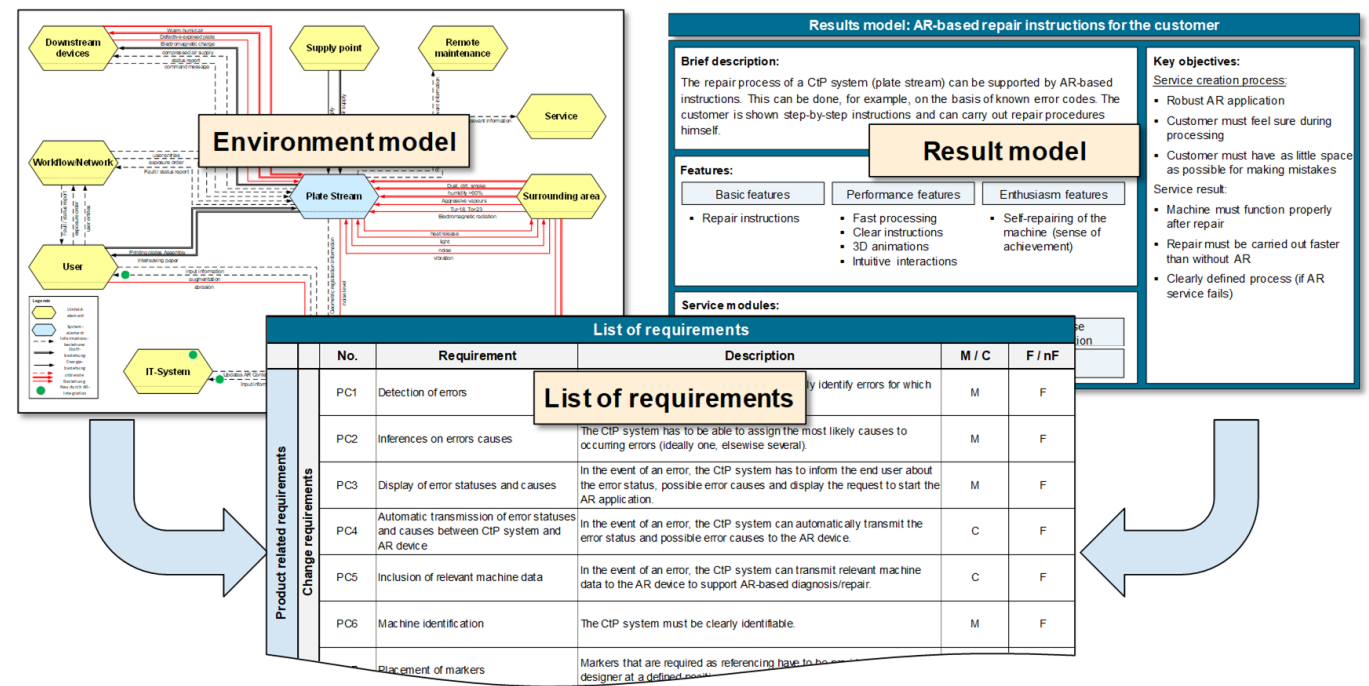

Figure 5. Derivation of requirements from the environment and result model

Considering the strong interdependencies between AR and environmental influences, as described in Section 1.2., it is crucial to anticipate and analyse the environment in which the AR system will be used. The environment model distinguishes between the system of interest (e.g. the product service system to be developed), which is considered as a "black box", and elements of the environment (e.g. user, 
surrounding, AR device) related to the system of interest. The interrelations between the system of interest and the elements of the environment are represented as either information, energy or material flows. Influences with a disturbing impact on the system operation (e.g. dust, vibrations) are marked as such. In case an existing product is enhanced by an AR-based service, the focus of the environment model will often be on identifying adjustment requirements. Based on the existing environment model of the product, new environmental elements and their influences that occur due to the integration of the AR-based services are added. In the environment model, these elements and influences are highlighted by a green dot. The identification of requirements based on the environment model is supported by a specific set of guiding questions of which some examples are presented below:

- Are there any new environmental elements that need to be added due to the integration of AR functionalities?

- How do these elements interact with the system of interest?

- Which adaptation requirements result from the environmental elements and their influences?

- Are there any conflicts that need to be taken into account?

The requirements of the result and the environment models are added to the list of requirements, which is divided into three sections: Product-related requirements include the original requirements of the existing product as well as those that result from the adaptation needs (e.g. enabling communication with an AR device), while service-related requirements focus on the provision of the service and the necessary infrastructure (e.g. ensuring that the customer can contact a service technician if the repair process has not been successful), and AR-related requirements refer to the AR application (e.g. user interaction) as well as the AR device (e.g. ergonomics, connectivity). Besides the result and environment model, a set of guiding questions supports the identification of additional requirements for each section.

\subsection{Function analysis}

Based on the list of requirements, the functions of the product service system are defined, with the term function referring to the required relationship between input and output parameters in order to fulfil a specific task. The overall function of the product service system is gradually divided into sub-functions, resulting in a hierarchically ordered function structure. A distinction is made between product-relevant functions (e.g. detecting failures) that address the physical product and service-relevant functions (e.g. documenting repair steps) that concern the process of providing the service. In addition, functions that are relevant for the usage of $A R$ (e.g. showing repair instructions) are highlighted by a green dot. In case an existing product is to be enhanced by an AR-based service, it is recommended to use the existing function structure of the product as a starting point for the function analysis. Figure 6 shows an excerpt of a function structure.

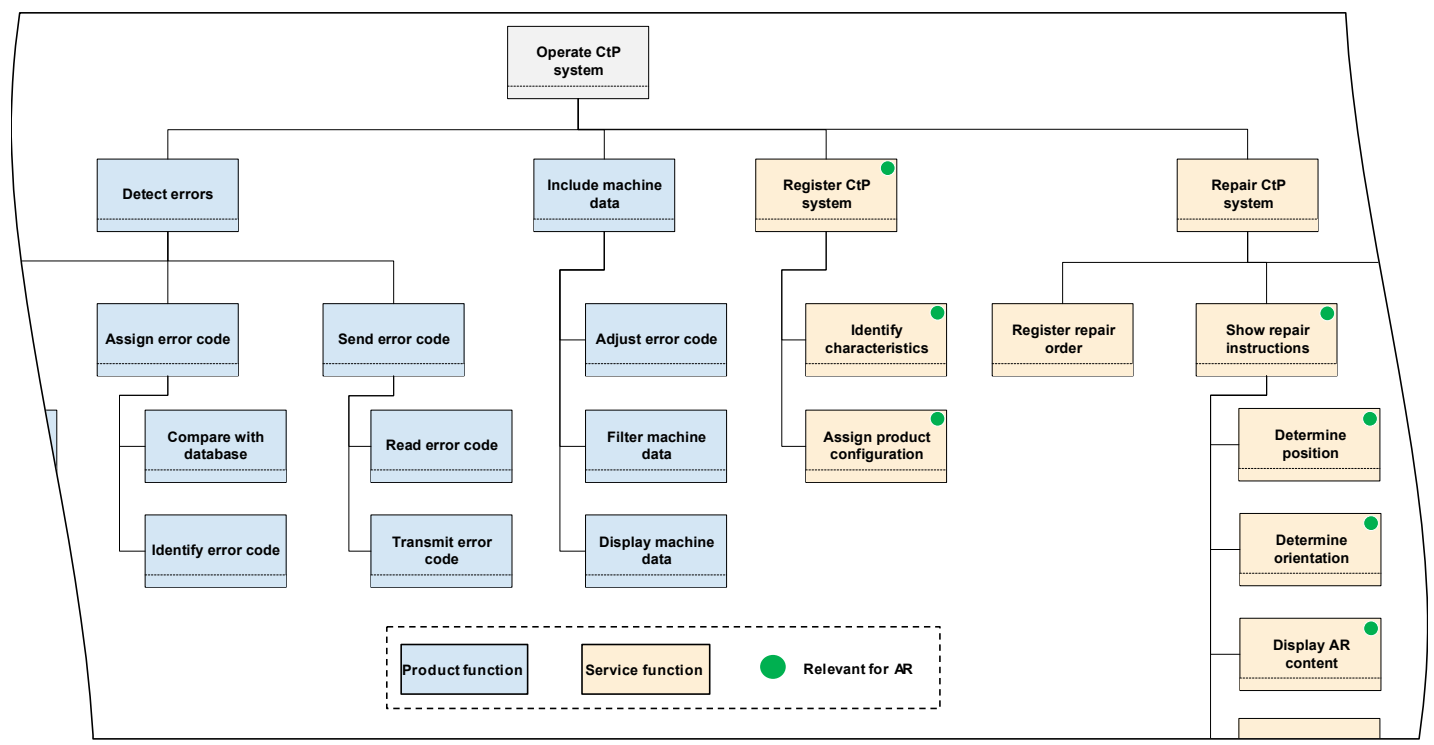

Figure 6. Function structure containing service- and product-relevant functions 


\subsection{Synthesis}

The transition from analysis (see Sections 2.3. and 2.4.) to synthesis is mainly based on the function structure. With the help of tools such as the morphological matrix by Zwicky (1949), solutions for fulfilling the functions can be determined (e.g. WiFi module allowing to fulfil the function "connect machine to AR device"). By applying principles of systems thinking, each solution can be considered as a system element, being a discrete part of a system, which can be implemented to fulfil specified requirements (ISO, 2002). To describe the system architecture in terms of the physical product, the active structure is used, according to the notation of CONSENS. In contrast to the environment model, the system is considered as a "white box" allowing to make the interdependencies within the system visible. The active structure contains the system elements, their attributes as well as the relations between the system elements (material, energy and information flows, and logical relations). In the context of AR-based product service systems, the active structure is used to analyse and incorporate adjustments that need to be made to the physical product (e.g. adding an optical marker to a machine to support the tracking of the AR device). The adjustments are usually based on new product-relevant functions that have been added to the function structure in the function analysis. Adjustments of the active structure can result in new system elements or flows and are provided with a green dot, as can be seen in Figure 7.

Since the active structure only provides a static view, another model is needed to describe the behaviour of the product. For this purpose, the behaviour model is used which contains states, state transitions and events that initiate state transitions. In the context of AR-based product service systems, the interconnections between the physical product and the AR device can be considered by using the behaviour model. As shown in Figure 7, when entering the error state, the CtP system sends information on the error code to the AR device which in turn automatically selects appropriate repair instructions according to the present error code. For analysing adjustments, it is again recommended to use the behaviour model of the existing product as a starting point.

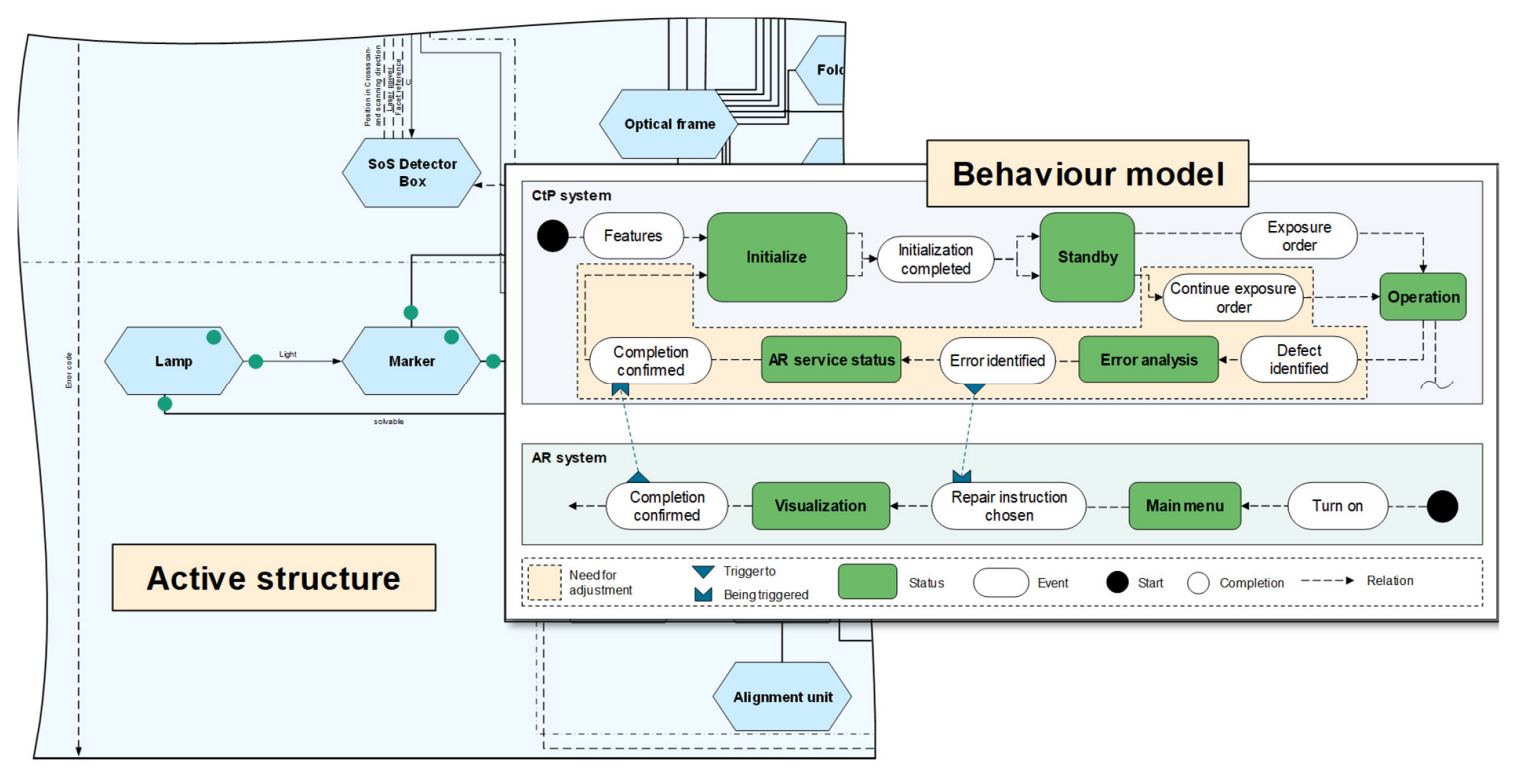

Figure 7. Examining adaptation needs in active structure and behaviour models

Analogous to the relation between product-relevant functions and system elements, the service-relevant functions are translated into process steps of the service. Being the link between the potential and the result dimension of a service, the service processes describe the way to achieve the service goal defined in the result model. In the literature, there are several approaches taking into account a procedural view of the service. The most common approach in this context is probably the Service Blueprinting (Shostack, 1984), which serves as a basis for the process model presented in this paper. By using 
different lanes, the process model distinguishes between activities done by the product service provider and by the customer. It further differentiates whether the activities are visible or invisible from a customer's point of view. As can be seen in Figure 8, the lanes are separated by the line of interaction (i.e. process steps above this line are done by the customer) and the line of visibility (i.e. process steps above this line are visible to the customer). In addition to the traditional Service Blueprint, the process model allows to illustrate AR-relevant activities that are directly related to the use of an AR device. When designing the process, it is important to ensure that all previously identified service modules (result model) and service-related functions (function structure) are covered by the modelled process. The process model and behaviour model are closely interlinked. For example, while events described in the behaviour model can trigger service processes (e.g. machine failure leads to starting a repair process), events in the process model can also initiate a new state in behaviour (e.g. machine returning to operating mode after a successful repair process). Here, the strong interdependencies between product and service become particularly apparent.

The potential dimension of a service is represented by the resource model that refers to the activities of the process model and assigns relevant resources to them. For this purpose, a matrix representation is recommended, as shown in Figure 8. Besides tangible resources such as necessary equipment, it is advisable to also include intangible resources in terms of skills and knowledge, since the development and provision of AR-based services will often require new competencies. By also considering the usage intensity of each resource (i.e. how often a resource is used, evaluated on a scale of 1 to 4 ), the resource model allows to further assess if the service processes are reasonable. This is particularly important due to fact that with AR-based services value-adding activities will often be transferred to the customer (e.g. repairing a machine) (Jost et al., 2017).

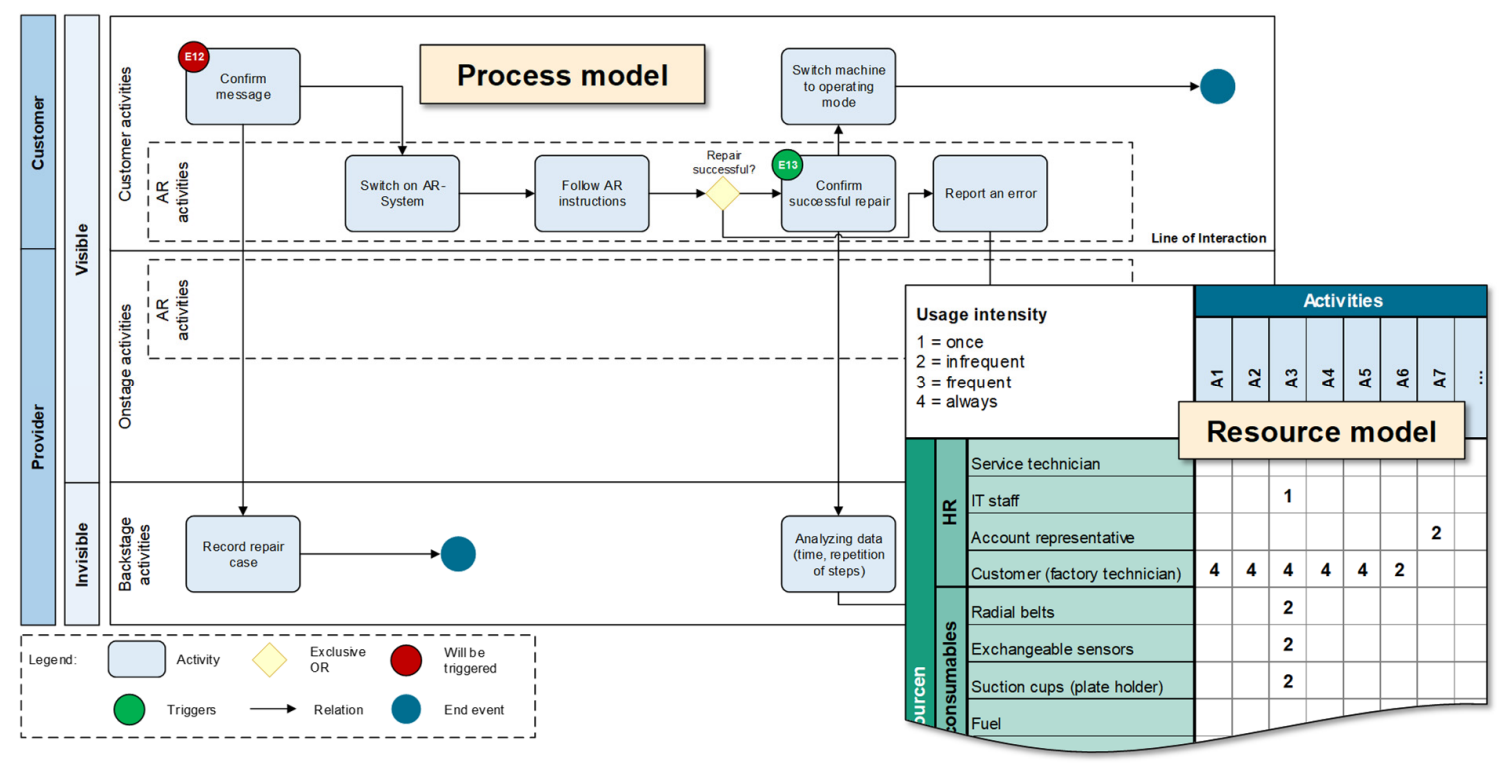

Figure 8. Specifying service-relevant aspects in the process and resource models

\subsection{Planning of action}

As shown in the previous sections, the synthesis reveals specific adaptation needs that have to be considered. For this purpose, a plan of action is required that contains a prioritization of the measures needed to implement the AR-based product service system. Based on the experience gained from the research project AcRoSS, it is advisable to arrange the measures in the form of a roadmap.

In addition to the partial models, a so-called AR Configuration Canvas, depicted in Figure 9, is used to support the derivation of measures and the communication between the different domains involved. The AR Configuration Canvas comprises several layers that are successively defined during the specification process, described in Sections 2.3.-2.5. The top layer contains the AR application scenario that should be 
implemented. Concerning the technical complexity, a distinction is made if the virtual information has a three-dimensional relation to the environment (Augmented Reality) or if the virtual content is displayed without being spatially integrated into the surroundings (Assisted Reality). This decision usually determines the types of $A R$ devices that are suitable. The AR Configuration Canvas distinguishes between smart glasses (either monocular or binocular), handheld systems (smartphones or tablets) and stationary AR projection systems. The data pool layer defines where the necessary data for the AR application is stored (e.g. device storage, remote server). In the layer below, the data is specified concerning type (e.g. 3D graphics, audio files) and content (e.g. stepper motor, repair instructions). The layer at the bottom describes the source of the data. For example, this could be the physical system of which 3D graphics are needed or an IT system containing specific repair instructions. By using logical relations, the constructs within the layers are connected. Based on the AR-Configuration Canvas, it can be determined which data or infrastructure already exists and where action is required. The identified needs for action can then be translated into specific measures to be taken in the subsequent development process.

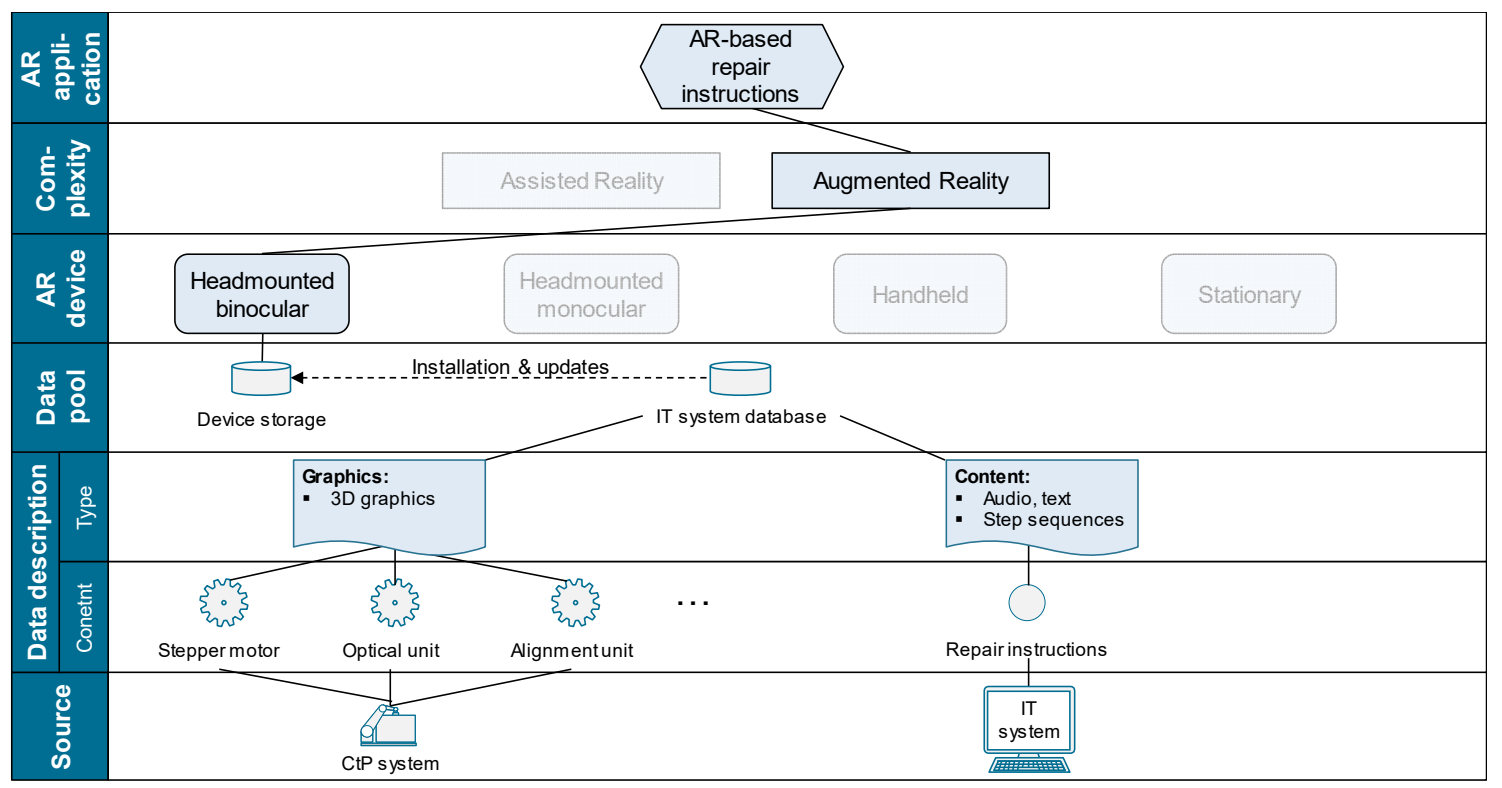

Figure 9. AR Configuration Canvas

\section{Summary and outlook}

Due to the complexity of the design process, the variety and diversity of the domains involved and the technology-specific challenges of AR, the conception of AR-based product service systems is by no means trivial. Based on these findings, a semi-formal specification technique for AR-based product service systems has been presented, consisting of a modeling concept and a procedure model. By using a set of different partial models, the modeling concept allows to describe the most important aspects of a product service system (e.g. functions, requirements), taking into account the technology-specific requirements of AR. The procedure model provides instructions on a reasonable sequence, according to which the partial models of the modeling concept should be implemented. By enabling transparency regarding the interdependencies between product, service and AR functionalities, the specification technique supports the design process and serves as a basis for the interdisciplinary communication between the domains involved. Considering the competitive advantages that result from aligning business model and service offerings (Kindström, 2010), further research will focus on the integration of business model aspects into the specification process.

\section{Acknowledgment}

Parts of this research and development work was carried out in the research project "Instrumentarium zur Implementierung von Augmented-Reality-basierten Produkt-Service-Systemen" (AcRoSS) (Instruments for the 
implementation of Augmented Reality based product service systems). The project has been funded by the German Federal Ministry for Economic Affairs and Energy (BMWi). The authors would like to thank the project committee for their advice.

\section{References}

acatech - National Academy of Science and Engineering (2015), Smart Service Welt - Recommendations for the Strategic Initiative Web-based Services for Businesses, final report, Berlin.

Aurich, J.C., Schweitzer, E. and Fuchs, C. (2007), "Life Cycle Management of Industrial Product-Service Systems", In: Takata, S. and Umeda, Y. (Eds.), Advances in Life Cycle Engineering for Sustainable Manufacturing Businesses, Springer, London. https://doi.org/10.1007/978-1-84628-935-4_30

Azuma, R.T. (1997), “A Survey of Augmented Reality”, Presence: Teleoperators and Virtual Environments, Vol. 6. No. 4, pp. 355-385. https://doi.org/10.1162/pres.1997.6.4.355

Blau, B., Burke, B., Searle, S. and Cearley, D.W. (2017), Top 10 Strategic Technology Trends for 2017 - Virtual and Augmented Reality, Gartner, Stamford.

Broy, M. (2010), Cyber-Physical Systems, Springer, Berlin. https://doi.org/10.1007/978-3-642-14901-6

Bruhn, M. and Stauss, B. (2009), "Kundenintegration im Dienstleistungsmanagement - Eine Einführung in die theoretischen und praktischen Problemstellungen", In: Bruhn, M. and Stauss, B. (Eds.), Kundenintegration, Gabler, Wiesbaden. https://doi.org/10.1007/978-3-8349-9407-3_1

Craig, A.B. (2013), Understanding Augmented Reality, Elsevier, Waltham.

Digi-Capital (2017), After mixed year, mobile AR to drive \$108 billion VR/AR market, Digi-Capital, Menlo Park.

Gausemeier, J., Rammig, F.J. and Schäfer, W. (2014), Design Methodology for Intelligent Technical Systems Develop Intelligent Technical Systems of the Future, Springer, Berlin. https://doi.org/10.1007/978-3-64245435-6

Glockner, H., Jannek, K., Mahn, J. and Theis, B. (2014), Augmented Reality in Logistics - Changing the Way We See Logistics, DHL Customer Solutions \& Innovation, Troisdorf.

Gräßle, M., Thomas, O. and Dollmann, T. (2010), "Vorgehensmodelle des Product-Service Systems Engineering", In: Thomas, O., Loos, P. and Nüttgens, M. (Eds.), Hybride Wertschöpfung, Springer, Berlin. https://doi.org/10.1007/978-3-642-11855-5_5

Herterich, M., Uebernickel, F. and Brenner, W. (2015), “The Impact of Cyber-physical Systems in Industrial Services in Manufacturing", Proceedings of the 7th Industrial Product-Service Systems Conference, St. Etienne, France, May 21-22, Elsevier, Waltham, pp. 323-328. https://doi.org/10.1016/j.procir.2015.02.110

ISO (2002), ISO 15288 Systems engineering, International Standards Organisation, Geneva, Switzerland.

Jost, J., Kirks, T., Mättig, B., Sinsel, A. and Trapp, T.U. (2017), "Der Mensch in der Industrie - Innovative Unterstützung durch Augmented Reality”, In: Vogel-Heuser, B., Bauernhansl, T. and ten Hompel, M. (Eds.), Handbuch Industrie 4.0, Springer, Berlin. https://doi.org/10.1007/978-3-662-45279-0_86

Kano, N., Seraku, N., Takahashi, F. and Tsuji, S. (1984), “Attractive Quality and Must-be Quality”, Journal of the Japanese Society for Quality Control, Vol. 14 No. 2, pp. 39-48.

Kindström, D. (2010), "Towards a service-based business model - Key aspects for future competitive advantage", European Management Journal, Vol. 28 No. 6, pp. 479-490. https://doi.org/10.1016/j.emj.2010.07.002

Klinger, S. and Becker, M. (2012), "Formale Modellierung von Komponenten und Abhängigkeiten zur Konfiguration von Product-Service-Systems", Enterprise Modelling and Information Systems Architectures, pp. 114-140.

Leimeister, J.M. (2012), Dienstleistungsengineering und -management, Springer, Berlin. https://doi.org/10.1007/978-3-642-27983-6

Li, M.M., Peters, C. and Leimeister, J.M. (2016), "Digitale Service-Systeme”, In: Gassmann, O. and Sutter, P. (Eds.), Digitale Transformation im Unternehmen gestalten, Carl Hanser Verlag, München. https://doi.org/10.3139/9783446451148.003

Milgram, P., Takemura, H., Utsumi, A. and Kishino, F. (1994), “Augmented Reality - A class of displays on the reality-virtuality continuum”, Proceedings of SPIE Vol. 2351, Telemanipulator and Telepresence Technologies, December 21, 1994. https://doi.org/10.1117/12.197321

Porcelli, I., Rapaccini, M., Espindola, D.B. and Pereira, C.E. (2013), "Innovating Product-Service Systems through Augmented Reality - A selection model”, In: Shimomura, Y. and Kimita, K. (Eds.), The philosopher's stone for sustainability, Springer, Berlin. https://doi.org/10.1007/978-3-642-32847-3

Porter, M.E. and Heppelmann, J.E. (2017), “A Manager's Guide to Augmented Reality”, Harvard Business Review, Vol. 95 No. 6, pp. 45-57.

Röltgen, D., Wortmann, F., Anacker, H. and Dumitrescu, R. (2017), "Identifikation von Potentialen für Augmented-Reality-basierte Produkt-Service-Systeme", 13. Symposium für Vorausschau und 
Technologieplanung, Berlin, Germany, November 23-24, HNI-Verlagsschriftenreihe Band 374, Paderborn, pp. 129-143.

Rüßmann, M., Lorenz, M., Gerbert, P., Waldner, M., Justus, J. et al. (2015), Industry 4.0 - The Future of Productivity and Growth in Manufacturing Industries, Boston Consulting Group, Boston.

Shostack, L.G. (1984), "Designing Services That Deliver”, Harvard Business Review, Vol. 62 No. 1, pp. 133-139.

Tsai, W.T. (2005), "Service-oriented system engineering: a new paradigm", IEEE International Workshop on Service-Oriented System Engineering, pp. 3-6. https://doi.org/10.1109/SOSE.2005.34

Tukker, A. and Tischner, U. (2006), "Product-services as a research field - Past, present and future. Reflections from a decade of research", Journal of Cleaner Production, Vol. 14 No. 17, pp. 1552-1556. https://doi.org/10.1016/j.jclepro.2006.01.022

Zwicky, F. (1949), "Morphologische Astronomie", Physikalische Blätter, Vol. 5 No. 1, pp. 4-10. https://doi.org/10.1002/phbl.19490050102

Daniel Röltgen, M.Sc.

Fraunhofer Research Institute for Mechatronic Systems Design, Product Engineering

Zukunftsmeile 1, 33102 Paderborn, Germany

Email: daniel.roeltgen@iem.fraunhofer.de 